\title{
Chronic kidney disease, albuminuria and socioeconomic status in the Health Surveys for England 2009 and 2010
}

\section{Simon D.S. Fraser'1, Paul J. Roderick', Grant Aitken², Marilyn Roth ${ }^{3}$, Jennifer S. Mindell ${ }^{3}$, Graham Moon'2, Donal O'Donoghue ${ }^{4}$}

${ }^{1}$ Academic Unit of Primary Care and Population Sciences, Faculty of Medicine, University of Southampton, South Academic Block, Southampton General Hospital, Tremona Road, Southampton, Hampshire SO16 6YD, UK

${ }^{2}$ Geography and Environment, University of Southampton, Highfield, Southampton SO17 1BJ, UK

${ }^{3}$ Research Department of Epidemiology \& Public Health, UCL (University College London), London WC1E 6BT, UK

${ }^{4}$ Department of Renal Medicine, Salford Royal Foundation Trust, Salford M6 8HD, UK

Address correspondence to Simon D.S. Fraser, E-mail: s.fraser@soton.ac.uk

\begin{abstract}
Background Renal replacement therapy rates are inversely related to socioeconomic status (SES) in developed countries. The relationship between chronic kidney disease (CKD) and SES is less clear. This study examined the relationships between SES and CKD and albuminuria in England.

Methods Data from the Health Survey for England 2009 and 2010 were combined. The prevalence of CKD 3-5 and albuminuria was calculated, and logistic regression used to determine their association with five individual-level measures and one area-level measure of SES.

Results The prevalence of CKD 3-5 was 5.2\% and albuminuria 8.0\%. Age-sex-adjusted CKD 3-5 was associated with lack of qualifications [odds ratio (OR) 2.27 (95\% confidence interval 1.40-3.69)], low income [OR 1.50 (1.02-2.21)] and renting tenure [OR 1.36 (1.01-1.84)]. Only tenure remained significant in fully adjusted models suggesting that co-variables were on the causal pathway. Albuminuria remained associated with several SES measures on full adjustment: low income [OR 1.55 (1.14-2.11)], no vehicle [OR 1.38 (1.05-1.81)], renting [OR 1.31 [1.03-1.67)] and most deprived area-level quintile [OR 1.55 (1.07-2.25)].

Conclusions CKD 3-5 and albuminuria were associated with low SES using several measures. For albuminuria this was not explained by known measured causal factors.
\end{abstract}

Keywords chronic kidney disease, epidemiology, socioeconomic factors

\section{Background}

Chronic kidney disease (CKD) is a global public health problem with the prevalence of CKD stage $1-5$ of $10-16 \%$ in adults. ${ }^{1-4} \mathrm{CKD}$ is defined and staged by level of kidney function (estimated glomerular filtration rate, eGFR) and the presence of markers of kidney damage (most commonly albuminuria). ${ }^{5}$ Both eGFR and albuminuria are strong independent risk factors for all-cause and cardiovascular disease (CVD) mortality; ${ }^{6,7}$ progression to end-stage renal disease (ESRD); ${ }^{8}$ need for renal replacement therapy (RRT, dialysis and renal transplant) and acute kidney injury. ${ }^{8}$

Understanding inequalities in CKD is important in guiding strategies for prevention, detection and intervention. There is an inverse relationship between RRT rates and socioeconomic status (SES) in the UK and in other countries, whether using area-level deprivation measures as a proxy for individual status ${ }^{9-14}$ or individual socioeconomic measures. ${ }^{15}$ The relationship between CKD and SES is less clear. Nationally representative surveys in some (but not all) developed countries

\footnotetext{
Simon D.S. Fraser, Specialty Registrar in Public Health

Paul J. Roderick, Professor of Public Health

Grant Aitken, PhD Student

Marilyn Roth, Research Associate

Jennifer S. Mindell, Clinical Senior Lecturer

Graham Moon, Professor of Spatial Analysis in Human Geography

Donal O'Donoghue, Professor of Renal Medicine
} 
(including those with and without national health services) have shown variation in CKD prevalence by SES, both within and between countries. ${ }^{16}$ Initial analysis of the 2009 and 2010 Health Surveys for England [HSEs, nationally representative surveys similar to US National Health and Nutrition Examination Surveys (NHANES)] showed mixed evidence for variation of $\mathrm{CKD}$ prevalence by area-level deprivation status, depending on severity of $\mathrm{CKD} .^{17,18}$ Data from NHANES III demonstrated the association between microalbuminuria and poverty, ${ }^{19}$ but no evidence is available in the UK on the relationship between albuminuria and SES. The association between low SES and increased risk of CKD diagnosis $^{20}$ and increased severity of CKD at presentation to renal services $^{21}$ has been demonstrated in the UK. Any observed variations in the CKD prevalence may be explained by differences in lifecourse exposures harmful to the kidney, such as foetal environment, environmental toxins, tobacco, obesity, hypertension and diabetes; and access to and use of health services. However, consideration needs to be given to the different measures of SES used and limitations of area-level proxies. This study aimed to provide detailed analysis of the associations of several socioeconomic factors (using both arealevel and individual measures) with CKD stage 3-5, using the Chronic Kidney Disease Epidemiology Collaboration (CKDEPI) equation to estimate GFR, and with albuminuria in the 2009 and 2010 HSEs. ${ }^{22}$

\section{Methods}

Full details of HSE methods, measurement of non-CKD variables and response rates are given in the HSE reports. ${ }^{17,18}$ A random, nationally representative sample was selected each year using a stratified, two-stage sample of private addresses. Participants completed an interview questionnaire; most consented to a nurse visit. In the 2009 or 2010 HSE, a valid urine sample was obtained from $88 \%$ of men and $86 \%$ of women aged 16 and over who had a nurse visit, and a non-fasting blood sample from $77 \%$ of men and $73 \%$ of women. Approval was obtained from the Oxford B Research Ethics Committee for both surveys (HSE 2009 ref 08/H0605/103, HSE 2010 ref 09/H0605/73).

Socioeconomic factors selected included: (1) occupation using National Statistics Socioeconomic Classification ${ }^{23}$ [NS-SEC, in three categories: high (managerial and professional occupations), middle (intermediate occupations) and low (routine and manual occupations)]; (ii) qualifications grouped as: degree (NVQ4/NVQ5/Degree or equivalent), below degree (higher education below degree or NVQ3/GCE A Level equivalent or NVQ2/GCE O Level equivalent or NVQ1/CSE other grade) and none (no qualification); (iii) household income tertiles; (iv) household tenure (owned or rented accommodation); (v) access to motor vehicle within the household (any versus none) and (vi) area-level deprivation [using Index of Multiple Deprivation 2007 (IMD) national quintiles: 1 least deprived (IMD 0.37 8.32), 2 (8.32-13.75), 3 (13.75-21.22), 4 (21.22-34.42) and 5 most deprived (34.42-85.46)]..$^{24}$

Ethnicity was self-defined using 2001 census categories. Hypertension was defined as self-reported pre-existing doctor diagnosis, survey-defined [high blood pressure identified (BP systolic $\geq 140 \mathrm{mmHg}$ and/or diastolic $\geq 90 \mathrm{mmHg}$ and/or taking medication for hypertension) at survey examination] and 'total' (doctor + survey diagnosed). Diabetes was treated similarly: survey-defined diabetes was $\mathrm{HBA}_{1 \mathrm{c}} \geq 6.5 \%$ at clinic visit. Body mass index (BMI) was classified as normal $\left(<25 \mathrm{~kg} / \mathrm{m}^{2}\right)$, overweight $\left(25-29.9 \mathrm{~kg} / \mathrm{m}^{2}\right)$ and obese $\left(\geq 30 \mathrm{~kg} / \mathrm{m}^{2}\right) .{ }^{25}$ Waist circumference was classified as: $<94 \mathrm{~cm}$, 94-102 cm (high) and $>102 \mathrm{~cm}$ (very high) for men, and $<80 \mathrm{~cm}, 80-88 \mathrm{~cm}$ (high) and $>88 \mathrm{~cm}$ (very high) for women. For South Asians, the waist circumference threshold was $90 \mathrm{~cm}$ (men) and $80 \mathrm{~cm}$ (women). ${ }^{25}$

Serum creatinine was assayed using an IDMS traceable enzymatic assay in a single laboratory [Clinical Biochemistry Department at the Royal Victoria Infirmary (RVI), Newcastleupon-Tyne]. Albuminuria was assessed using urinary albumin creatinine ratio (ACR), measured on a single random urine sample. Abnormal levels were divided into microalbuminuria (ACR $2.5-30 \mathrm{mg} / \mathrm{mmol}$ in men and $3.5-30 \mathrm{mg} / \mathrm{mmol}$ in women) and macroalbuminuria [ACR $>30 \mathrm{mg} / \mathrm{mmol}$ (in either sex)]. ${ }^{26}$ CKDEPI eGFR values were derived using the standard equation, ${ }^{22}$ a more accurate measure of true eGFR than the Modification of Diet in Renal Disease (MDRD) equation in routine use in the $\mathrm{UK}^{27}$ Details of laboratory analysis, internal quality control and external quality assurance are provided in HSE documentation. ${ }^{17,18}$ The Kidney Disease: improving Global Outcomes classification of CKD based on level of eGFR was used: Stage 1: eGFR $90 \mathrm{ml} / \mathrm{min} / 1.73 \mathrm{~m}^{2}$ or more with albuminuria, Stage 2: $60-89 \mathrm{ml} / \mathrm{min} / 1.73 \mathrm{~m}^{2}$ with albuminuria, Stage 3a: $45-59 \mathrm{ml} / \mathrm{min} / 1.73 \mathrm{~m}^{2}$, Stage $3 \mathrm{~b}$ : $30-44 \mathrm{ml} / \mathrm{min} / 1.73 \mathrm{~m}^{2}$, Stage $4: 15-29 \mathrm{ml} / \mathrm{min} / 1.73 \mathrm{~m}^{2}$ and Stage 5: $<15 \mathrm{ml} / \mathrm{min} / 1.73 \mathrm{~m}^{2}{ }^{28}$ Current guidelines recommend that CKD be defined on the basis of reduced eGFR present for at least 3 months. ${ }^{5,26,28}$ However, because of the cross-sectional nature of the HSEs, a single eGFR $<60 \mathrm{ml}$ / $\min / 1.73 \mathrm{~m}^{2}$ was used to define CKD stage $3-5$ in these analyses.

\section{Statistical analyses}

The prevalence by CKD stage included participants with both serum creatinine and urinary ACR data. Analyses of 
CKD and albuminuria associations used all participants with relevant data to maximize power and to allow analysis of albuminuria individually. Logistic regression models were used to examine the relationships between CKD and demographic, socioeconomic, lifestyle and clinical factors, adjusted for age and sex. Age was categorized as $<65$ and $\geq 65$. An age $\times$ sex interaction term was included in multivariable regression models following identification of an age $\times$ sex interaction for CKD 3-5 early in our analyses. Overall, CKD prevalence estimation accounted for weighting within gender to allow for gender differences in response. Non-response weights were used in all analyses. Despite low numbers from ethnic minorities, ethnicity is associated with variation in RRT rates, ${ }^{13,14}$ and ethnicity was therefore included as a potential confounder in multivariable analyses. Three dichotomized-dependent variables were investigated: CKD defined by the CKDEPI equation as eGFR $<60 \mathrm{ml} / \mathrm{min} / 1.73 \mathrm{~m}^{2}$ (Stage 3-5); the presence of micro- or macro-albuminuria and CKD stage $1-2$ defined as eGFR $>60 \mathrm{ml} / \mathrm{min} / 1.73 \mathrm{~m}^{2}$ with evidence of albuminuria. Sensitivity analyses were conducted in the white-only population, and, for albuminuria, in people without diabetes. For CKD 3-5, analyses were also conducted using the MDRD equation to define CKD.

Interactions of socioeconomic variables with age and sex were examined and also with diabetes in the albuminuria models. The final models were (i) age, sex and age $\times$ sex, (ii) age, sex, ethnicity and age $\times$ sex and (iii) age, sex, ethnicity, age $\times$ sex, smoking, BMI, doctor diagnosed hypertension and doctor diagnosed diabetes.

Odds ratios are presented with $95 \%$ confidence intervals (CIs) and $P$ values of $<0.05$ were considered statistically significant. All analyses, adjusted for the complex survey design, were performed using IBM SPSS Statistics version 19.

\section{Results}

The total combined sample size (unweighted) for the 2009 and 2010 HSE was 13065 individuals aged 16 and over. Sample characteristics (weighted for non-response) are shown in Table 1. In total, $5799(44.4 \%)$ respondents had a valid serum creatinine value, $7592(58.1 \%)$ had a valid ACR and $5318(40.7 \%)$ had both. Of the unweighted sample of 5799 individuals, $3186(54.9 \%)$ were female $(51.2 \%$ of the weighted sample). Of those excluded because they lacked a valid serum creatinine, 1994 (27.6\%) had no formal qualifications (compared with $20.6 \%$ in those included). Of those without valid ACR, 1239 (22.4\%) had no access to a motor vehicle and 1660 (30.2\%) had no qualifications (compared with 16.7 and 20.3\% in those included). Otherwise those included and those excluded were comparable with regard to SES.
The overall weighted prevalence of CKD stage $3-5$ was $303 / 5786(5.2 \%)$. The prevalence of any albuminuria was $8.2 \%$ in men and $7.5 \%$ in women [for macroalbuminuria, 0.3 and $0.5 \%$ respectively (only 22 people)]. Both CKD 3-5 and albuminuria prevalence was higher in people with low income, no access to a vehicle and no formal qualifications. Prevalence patterns for CKD 1-2 and CKD 3-5 with albuminuria were similar to those for overall albuminuria [although the number of people with CKD stage $3-5$ with albuminuria was low $(n=66)$ ] (Table 2).

Age-sex-adjusted CKD 3-5 was associated with lack of qualifications [odds ratio (OR) 2.27 (95\% CI 1.40-3.69)], low income [OR $1.50(1.02-2.21)]$ and renting household tenure[OR 1.36 (1.01-1.84) versus ownership]. Tenure remained significant in fully adjusted models. Albuminuria remained associated with several SES measures on full adjustment: low income [OR 1.55 (1.14-2.11)], no vehicle [OR 1.38 (1.05-1.81)], renting [OR 1.31 (1.03-1.67)], most deprived area-level quintile [OR 1.55 (1.072.25)] (Fig. 1 and Supplementary data, Appendix Table S1).

Table 3 shows the prevalence and associations for lifestyle and clinical factors, which might act as confounding/explanatory factors for the SES-CKD relationship. BMI, diabetes and hypertension were positively associated with $\mathrm{CKD}$ and albuminuria, whereas total cholesterol was not associated with either. HDL cholesterol was negatively associated with both. All SES measures were associated with smoking, type 2 diabetes, hypertension and obesity after age-sex adjustment (Supplementary data, Appendix Table S2). CKD 1-2 was associated with smoking, BMI, waist circumference, HDL cholesterol, diabetes and hypertension (data not shown).

A significant age $\times$ sex interaction $(P<0.05)$ was identified in the CKD models, with younger $(<65)$ females having greater odds of CKD compared with younger males but with no difference in older age groups. There were no significant interactions between age and SES in the CKD models or diabetes and SES in the albuminuria models.

There were no differences in these results in the sensitivity analyses for the white-only population, and, for albuminuria, in people without diabetes (data not shown).

The use of the MDRD equation in place of CKDEPI resulted in slightly different associations of CKD 3-5 with SES, with qualification level and vehicle ownership remaining associated in the fully adjusted model (Supplementary data, Appendix Table S3).

\section{Discussion}

\section{Main findings of this study}

This study found socioeconomic disparities in the prevalence of CKD stage 3-5, using the CKD-EPI equation to define 
Table 1. Sociodemographic and clinical characteristics of the weighted study sample

\begin{tabular}{|c|c|c|c|c|c|}
\hline \multirow[t]{2}{*}{ Variable } & \multirow[t]{2}{*}{ Category } & \multicolumn{2}{|c|}{$\begin{array}{l}\text { People with valid serum } \\
\text { creatinine value }\end{array}$} & \multicolumn{2}{|c|}{$\begin{array}{l}\text { People with urine albumin } \\
\text { creatinine ratio value }\end{array}$} \\
\hline & & Number & Column \% & Number & Column \% \\
\hline All & Aged 16+ & 5799 & 100 & 7592 & 100 \\
\hline \multirow[t]{5}{*}{ Age } & $16-34$ & 1756 & 30.3 & 1949 & 25.7 \\
\hline & $34-54$ & 2037 & 35.1 & 2844 & 37.5 \\
\hline & $55-64$ & 856 & 14.8 & 1218 & 16.0 \\
\hline & $65-74$ & 615 & 10.6 & 871 & 11.5 \\
\hline & $75+$ & 522 & 9.0 & 655 & 8.6 \\
\hline \multirow[t]{4}{*}{ Ethnicity } & White & 5244 & 90.4 & 6884 & 90.7 \\
\hline & South Asian & 243 & 4.2 & 285 & 3.8 \\
\hline & Black & 154 & 2.7 & 200 & 2.6 \\
\hline & Other & 139 & 2.4 & 160 & 2.1 \\
\hline \multirow[t]{2}{*}{ Sex } & Male & 2823 & 48.7 & 3667 & 48.3 \\
\hline & Female & 2963 & 51.1 & 3870 & 51.0 \\
\hline \multirow[t]{3}{*}{ Income tertile } & Lowest & 1393 & 24.0 & 1517 & 20.0 \\
\hline & Middle & 1617 & 27.9 & 1963 & 25.9 \\
\hline & Highest & 1829 & 31.5 & 2224 & 29.3 \\
\hline \multirow[t]{2}{*}{ Access to motor vehicle } & Yes & 4728 & 81.5 & 6280 & 82.7 \\
\hline & No & 1056 & 18.2 & 1256 & 16.5 \\
\hline \multirow[t]{3}{*}{ Qualification } & Degree & 1295 & 22.3 & 1761 & 23.2 \\
\hline & Below degree & 3296 & 56.8 & 4238 & 55.8 \\
\hline & None & 1197 & 20.6 & 1531 & 20.2 \\
\hline \multirow[t]{3}{*}{ Occupation (NS-SEC) } & High & 1894 & 32.7 & 2646 & 34.9 \\
\hline & Middle & 1203 & 20.7 & 1611 & 21.2 \\
\hline & Low & 2619 & 45.2 & 3207 & 42.2 \\
\hline \multirow[t]{5}{*}{ IMD Quintile } & 1. Least deprived & 1197 & 20.6 & 1683 & 22.2 \\
\hline & 2. & 1204 & 20.8 & 1601 & 21.1 \\
\hline & 3. & 1228 & 21.2 & 1627 & 21.4 \\
\hline & 4. & 1105 & 19.1 & 1442 & 19.0 \\
\hline & 5. Most deprived & 1051 & 18.1 & 1184 & 15.6 \\
\hline \multirow[t]{2}{*}{ Housing Tenure } & Own/mortgage & 3955 & 68.2 & 5389 & 71.0 \\
\hline & Rent/other & 1817 & 31.3 & 2148 & 28.3 \\
\hline \multirow[t]{3}{*}{ Smoking } & Never & 3126 & 53.9 & 4089 & 53.9 \\
\hline & Ex & 1429 & 24.6 & 2007 & 26.4 \\
\hline & Current & 1210 & 20.9 & 1423 & 18.7 \\
\hline \multirow[t]{3}{*}{ Body mass index (BMI) } & Normal & 1956 & 33.7 & 2468 & 32.5 \\
\hline & Overweight & 2047 & 35.3 & 2683 & 35.3 \\
\hline & Obese & 1314 & 22.7 & 1815 & 23.9 \\
\hline \multirow[t]{3}{*}{ Waist circumference } & Low & 2120 & 36.6 & 2701 & 35.6 \\
\hline & High & 1347 & 23.2 & 1761 & 23.2 \\
\hline & Very High & 2242 & 38.7 & 2938 & 38.7 \\
\hline \multirow[t]{2}{*}{ Total cholesterol } & $<5 \mathrm{mmol} / \mathrm{l}$ & 2675 & 46.1 & 2984 & 39.3 \\
\hline & $\geq 5 \mathrm{mmol} / \mathrm{l}$ & 3110 & 53.6 & 3719 & 49.0 \\
\hline \multirow[t]{2}{*}{ HDL cholesterol } & $<1.2 \mathrm{mmol} / \mathrm{l}$ & 1301 & 22.4 & 1591 & 21.0 \\
\hline & $\geq 1.2 \mathrm{mmol}$ & 4485 & 77.3 & 5809 & 76.5 \\
\hline \multirow[t]{3}{*}{ Albuminuria } & None & 4837 & 83.4 & 6896 & 90.8 \\
\hline & Micro & 399 & 6.9 & 601 & 7.9 \\
\hline & Macro & 22 & 0.4 & 39 & 0.5 \\
\hline \multirow[t]{2}{*}{ Diabetes } & No diabetes & 5370 & 92.6 & 6957 & 91.6 \\
\hline & Doctor diagnosed ${ }^{a}$ & 305 & 5.3 & 450 & 5.9 \\
\hline
\end{tabular}


Table 1. Continued

\begin{tabular}{|c|c|c|c|c|c|}
\hline \multirow[t]{2}{*}{ Variable } & \multirow[t]{2}{*}{ Category } & \multicolumn{2}{|c|}{$\begin{array}{l}\text { People with valid serum } \\
\text { creatinine value }\end{array}$} & \multicolumn{2}{|c|}{$\begin{array}{l}\text { People with urine albumin } \\
\text { creatinine ratio value }\end{array}$} \\
\hline & & Number & Column \% & Number & Column \% \\
\hline \multirow{5}{*}{ Hypertension } & Survey defined ${ }^{b}$ & 316 & 5.4 & 442 & 5.8 \\
\hline & Total $^{c}$ & 429 & 7.4 & 581 & 7.7 \\
\hline & No HT & 3800 & 65.5 & 4854 & 63.9 \\
\hline & Doctor diagnosed ${ }^{a}$ & 1387 & 23.9 & 1992 & 26.2 \\
\hline & Survey defined ${ }^{d}$ & 1542 & 26.6 & 2112 & 27.8 \\
\hline \multirow{3}{*}{ Chronic kidney disease } & Total $^{c}$ & 1980 & 34.1 & 2683 & 35.3 \\
\hline & Yes & 303 & 5.2 & - & - \\
\hline & No & 5483 & 94.6 & - & - \\
\hline
\end{tabular}

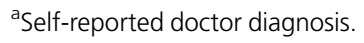

${ }^{b} \mathrm{HBA}_{1 \mathrm{c}} \geq 6.5 \%$.

'Doctor or survey diagnosed.

dIdentified as high blood pressure (BP systolic $\geq 140 \mathrm{mmHg}$ and/or diastolic $\geq 90 \mathrm{mmHg}$ and/or taking medication for hypertension).

Table 2. Directly age-sex standardized prevalence (\%) of CKD stage 3-5 and albuminuria by sociodemographic characteristics

\begin{tabular}{|c|c|c|c|c|c|c|}
\hline Variable & Category & $\begin{array}{l}\text { CKD 3-5 (eGFR } \\
\left.<60 \mathrm{ml} / \mathrm{min} / 1.73 \mathrm{~m}^{2}\right) \\
\text { Weighted }(\mathrm{n}=5786)\end{array}$ & $\begin{array}{l}\text { Albuminuria } \\
\text { (any) } \\
\text { Weighted } \\
(\mathrm{n}=7529)\end{array}$ & $\begin{array}{l}\text { Albuminuria } \\
(C K D \text { 1-2) } \\
\text { Weighted } \\
(\mathrm{n}=355)\end{array}$ & $\begin{array}{l}\text { Albuminuria (in people } \\
\text { with CKD 3-5) } \\
\text { Weighted }(\mathrm{n}=66 \text { ) }\end{array}$ & $\begin{array}{l}\text { Total numbers } \\
\text { in row }\end{array}$ \\
\hline All & Aged 16+ & 5.2 & 8.0 & 7.1 & 1.1 & \\
\hline \multirow[t]{4}{*}{ Ethnicity } & White & 5.6 & 8.1 & 7.2 & 1.3 & 5244 \\
\hline & South Asian & 1.1 & 6.4 & 6.3 & 0.2 & 243 \\
\hline & Black & 2.7 & 6.8 & 6.5 & 0.6 & 154 \\
\hline & Other & 0.7 & 6.2 & 6.2 & 0.1 & 137 \\
\hline \multirow[t]{3}{*}{ Income tertile } & Lowest & 6.5 & 8.7 & 7.5 & 1.5 & 1393 \\
\hline & Middle & 6.0 & 8.3 & 7.3 & 1.4 & 1617 \\
\hline & Highest & 3.0 & 6.9 & 6.5 & 0.6 & 1830 \\
\hline Access to motor & Yes & 4.4 & 7.7 & 7.0 & 1.0 & 4729 \\
\hline Vehicle & No & 8.6 & 9.2 & 7.7 & 2.0 & 1057 \\
\hline \multirow[t]{3}{*}{ Qualification } & Degree & 2.5 & 7.1 & 6.7 & 0.5 & 1295 \\
\hline & Below degree & 3.6 & 7.3 & 6.7 & 0.8 & 3297 \\
\hline & None & 12.4 & 10.8 & 8.9 & 2.9 & 1192 \\
\hline Occupation & High & 4.6 & 7.8 & 7.0 & 1.1 & 1894 \\
\hline \multirow[t]{2}{*}{ (NS-SEC) } & Middle & 6.1 & 8.0 & 7.1 & 1.3 & 1203 \\
\hline & Low & 5.7 & 8.2 & 7.3 & 1.3 & 2343 \\
\hline \multirow[t]{7}{*}{ IMD quintile } & 1. (IMD 0.37-8.31) & 6.0 & 8.2 & 7.3 & 1.4 & 1196 \\
\hline & Least deprived & & & & & \\
\hline & 2. (IMD 8.32-13.74) & 6.3 & 8.5 & 7.5 & 1.4 & 1204 \\
\hline & 3. (IMD 13.75-21.21) & 4.8 & 7.8 & 7.0 & 1.1 & 1229 \\
\hline & 4. (IMD 21.22-34.41) & 4.6 & 7.7 & 6.8 & 1.1 & 1105 \\
\hline & 5. (IMD 34.42-85.46) & 3.9 & 7.5 & 6.8 & 0.9 & 1051 \\
\hline & Most deprived & & & & & \\
\hline \multirow[t]{2}{*}{ Housing tenure } & Own/mortgage & 5.7 & 8.1 & 7.2 & 1.3 & 3956 \\
\hline & Rent/other & 3.9 & 7.6 & 6.9 & 0.9 & 1816 \\
\hline
\end{tabular}




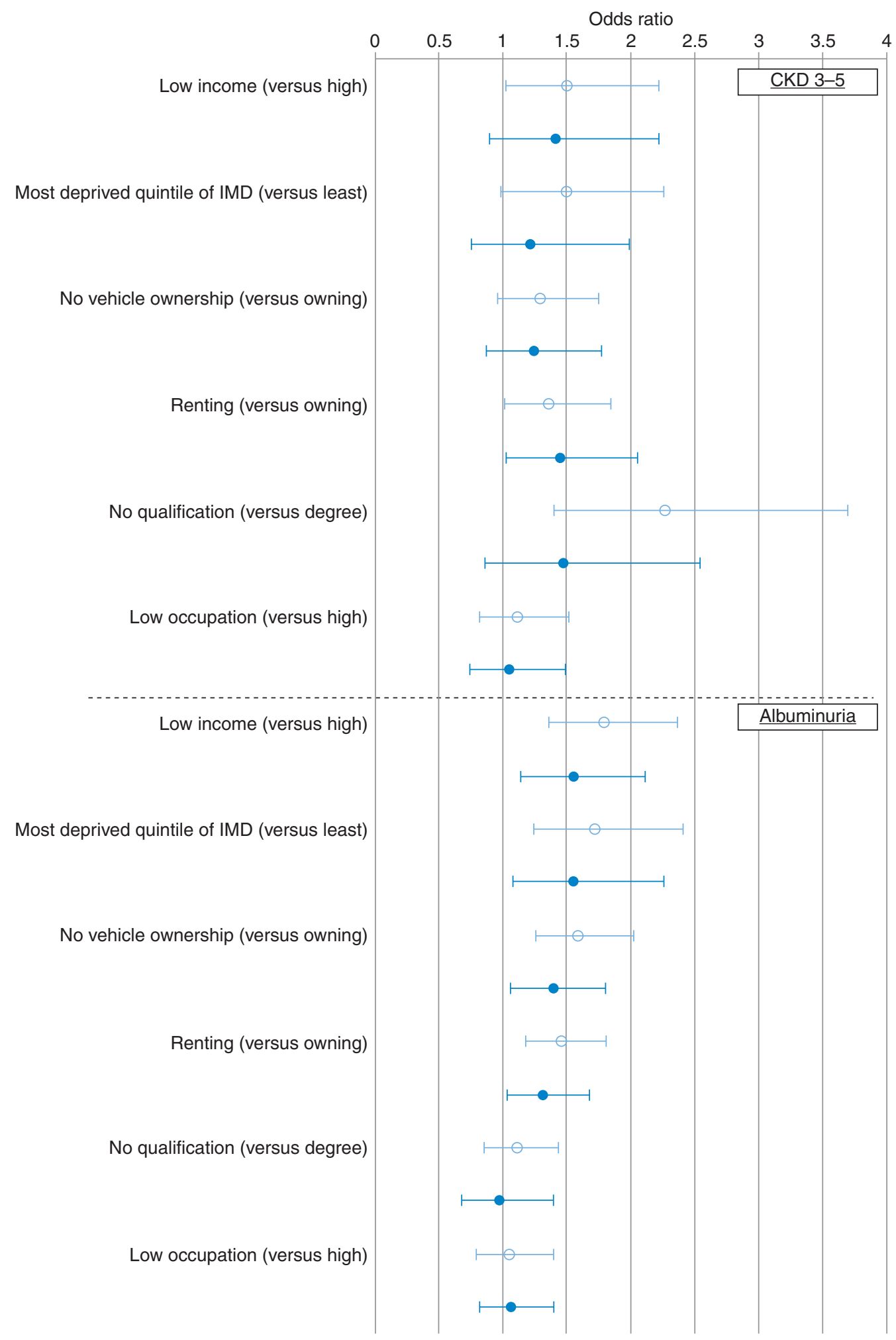

Fig. 1. Associations of CKD stage 3-5 and Albuminuria with measures of SES (age-sex and fully adjusted models). Open circle marker: age-sex adjusted. Closed circle marker: fully adjusted model. 
Table 3. Prevalence and age-/sex/age $\times$ sex-adjusted associations of CKD stage 3-5 and albuminuria (all albuminuria cases) with behavioural and clinical factors

\begin{tabular}{|c|c|c|c|c|c|c|c|}
\hline \multirow[t]{2}{*}{ Variable } & \multirow[t]{2}{*}{ Category } & \multicolumn{3}{|l|}{$C K D 3-5$} & \multicolumn{3}{|l|}{ Albuminuria } \\
\hline & & Prevalence (\%) & Odds ratio $(95 \% \mathrm{Cl})$ & Pvalue & Prevalence (\%) & Odds ratio $(95 \%$ CI) & Pvalue \\
\hline \multirow[t]{3}{*}{ Smoking } & Current & 4.5 & 1 & 0.854 & 8.4 & 1 & 0.048 \\
\hline & Ex & 8.9 & $1.24(0.80-1.92)$ & & 9.7 & $0.85(0.63-1.15)$ & \\
\hline & Never & 2.4 & $1.02(0.62-1.65)$ & & 6.9 & $0.76(0.59-0.99)^{*}$ & \\
\hline \multirow[t]{3}{*}{ Body mass index (BMI) } & Normal & 2.3 & 1 & 0.001 & 6.6 & 1 & 0.048 \\
\hline & Overweight & 5.0 & $1.72(1.18-2.52)$ & & 6.7 & $1.11(0.86-1.43)$ & \\
\hline & Obese & 7.5 & $2.75(1.87-4.04)$ & & 8.4 & $1.33(1.01-1.75)^{*}$ & \\
\hline \multirow[t]{3}{*}{ Waist circumference } & Low & 2.1 & 1 & $<0.001$ & 6.4 & 1 & \\
\hline & High & 5.5 & $1.57(1.05-2.34)$ & & 7.7 & $1.10(0.83-1.45)$ & 0.636 \\
\hline & Very High & 7.9 & $1.97(1.38-2.81)$ & & 9.2 & $1.27(0.99-1.62)$ & 0.051 \\
\hline \multirow[t]{2}{*}{ Total cholesterol } & $<5 \mathrm{mmol} / \mathrm{l}$ & 5.6 & 1 & 0.092 & 8.4 & 1 & \\
\hline & $\geq 5 \mathrm{mmol} / \mathrm{l}$ & 4.9 & $0.80(0.62-1.04)$ & & 8.0 & $0.90(0.73-1.09)$ & 0.251 \\
\hline \multirow[t]{2}{*}{ HDL cholesterol } & $<1.2 \mathrm{mmol} / \mathrm{l}$ & 6.9 & 1 & $<0.001$ & 10.0 & 1 & \\
\hline & $\geq 1.2 \mathrm{mmol}$ & 4.7 & $0.55(0.41-0.74)$ & & 7.6 & $0.73(0.58-0.93)^{* *}$ & 0.003 \\
\hline \multirow[t]{3}{*}{ Albuminuria } & None & 4.6 & 1 & $<0.001$ & - & - & - \\
\hline & Micro & 16.0 & $2.34(1.65-3.31)$ & & - & - & \\
\hline & Macro & 30.0 & $7.53(2.22-25.5)$ & & - & - & \\
\hline \multirow[t]{4}{*}{ Diabetes } & No diabetes & 4.4 & 1 & $<0.001$ & 7.0 & 1 & $<0.001$ \\
\hline & Doctor diagnosed ${ }^{a}$ & 15.5 & $3.83(2.74-5.35)$ & & 22.9 & $2.69(1.95-3.70)$ & \\
\hline & Survey defined ${ }^{b}$ & 16.8 & $4.33(3.14-5.99)$ & & 16.8 & $2.56(1.93-3.41)$ & \\
\hline & Total $^{\mathrm{c}}$ & 15.4 & $3.99(2.97-5.35)$ & & 20.4 & $2.50(1.89-3.66)$ & \\
\hline \multirow[t]{4}{*}{ Hypertension } & No hypertension & 2.1 & 1 & $<0.001$ & 5.2 & 1 & $<0.001$ \\
\hline & Doctor diagnosed ${ }^{a}$ & 13.1 & $5.56(4.37-7.09)$ & & 14.4 & $2.25(1.81-2.81)$ & \\
\hline & Survey defined $^{d}$ & 12.4 & $5.11(3.99-6.56)$ & & 9.6 & $2.13(1.69-2.69)$ & \\
\hline & Total $^{c}$ & 11.3 & $6.04(4.64-7.88)$ & & 13.3 & $2.04(1.60-2.89)$ & \\
\hline
\end{tabular}

Age-sex-adjusted odds ratios.

a Self-reported doctor diagnosis.

${ }^{b} \mathrm{HBA}_{1 \mathrm{c}} \geq 6.5 \%$.

'Doctor or survey diagnosed.

Identified as high blood pressure (BP systolic $\geq 140 \mathrm{mmHg}$ and/or diastolic $\geq 90 \mathrm{mmHg}$ and/or taking medication for hypertension).

CKD, for individual measures of SES. It also identified socioeconomic disparities in the prevalence of albuminuria, an independent predictor of poor outcomes, for a wide range of both individual and an area-level measures of SES.

Higher CKD 3-5 prevalence was associated with lack of qualifications, low income and housing tenure (renting) after adjusting for age and sex. These associations were not maintained after further adjustment for ethnicity, lifestyle and clinical variables (obesity, diabetes, hypertension and smoking), which are likely to be explanatory factors on the causal pathway. Higher albuminuria prevalence was associated with low income, lack of vehicle ownership, housing tenure (renting) and IMD, and these were maintained, though attenuated, after full adjustment, demonstrating independence from these key factors on the causal pathway.

\section{What is already known on this topic}

Our results support the findings of several other studies. A population-based case-control study in Sweden found an approximately doubled adjusted odds ratio of having CKD in families with only unskilled workers compared with families with at least one professional (after adjusting for age, sex, BMI, smoking, alcohol and aspirin or paracetamol use). ${ }^{29}$ A cross-sectional study in the UK of incident CKD presenting to renal services found increased risk of low eGFR $\left(<30 \mathrm{ml} / \mathrm{min} / 1.73 \mathrm{~m}^{2}\right)$ in areas with greater socioeconomic deprivation. ${ }^{21}$ Cross-sectional data from the Whitehall II cohort identified higher odds of low eGFR in lower occupational grades; this association was attenuated after adjustment for BMI and components of the metabolic syndrome; similar to our findings. ${ }^{30}$ The Atherosclerosis Risk in Communities 
(ARIC) study identified an association of CKD incidence with individual SES (occupation). ${ }^{31}$ White et al., comparing findings from nationally representative surveys in the USA and Australia, showed variation between countries, and, for the USA, between different ethnic groups, in associations between SES and CKD 3-5 prevalence. ${ }^{16}$ American non-Hispanic Whites with lower levels of education or in the lowest income quartile were more likely to have CKD compared with those with higher education levels, employed groups and those in the highest income quartile. ${ }^{16}$ In contrast, an Australian national survey did not demonstrate an association of CKD prevalence with SES (measured by education and income) after age-sex adjustment. ${ }^{16}$ The recent Quality Improvement in CKD trial in the UK identified the associations between deprivation (IMD) and CKD prevalence, though this was not considered 'clinically significant'. ${ }^{32}$ Reasons for these variations are likely to be complex, but may relate to differences in health-care systems or access to health care and primary prevention. ${ }^{16}$

\section{What this study adds}

There is little existing evidence on the relationship between albuminuria and SES. Data from NHANES III demonstrated the association between microalbuminuria and poverty in the USA (adjusted OR 1.18, 1.05-1.33), ${ }^{19}$ and similar associations have been shown with various measures of SES in a Malay population. ${ }^{33}$ To our knowledge, this is the first study to investigate the association between albuminuria and SES in a representative population sample in the UK. In unadjusted analyses, our data suggest socioeconomic inequalities in albuminuria distribution, both in those with eGFR $<60 \mathrm{ml} / \mathrm{min} /$ $1.73 \mathrm{~m}^{2}$ and those with eGFR above this level, which will influence differential propensity to progress. There are few data on the relationship between SES and CKD progression. The (ARIC) study in the USA identified that, for white men, living in the lowest compared with the highest SES area-level quartile was associated with increased risk of CKD progression (hazard ratio for elevated serum creatinine 1.6 (95\% CI 1.0-2.5). ${ }^{34}$ The reasons for finding association between SES and CKD and albuminuria may be partly related to the social distribution of underlying factors associated with CKD occurrence and progression, ${ }^{34}$ including obesity, ${ }^{35}$ smoking, type 2 diabetes $^{36}$ and hypertension. ${ }^{37}$ Persistence of the association for albuminuria after adjustment suggests other causal mechanisms (and or potential residual confounding) may apply. Albuminuria is a key determinant of progression and poor outcome in CKD, particularly when combined with other risk factors (type 2 diabetes and hypertension), which are more prevalent in lower socioeconomic groups. Other factors such as low birth weight ${ }^{38}$ and health care access (with variation by health system) also show socioeconomic patterns. ${ }^{39}$

\section{Limitations of this study}

Strengths of this study include the nationally representative nature of the 2009 and 2010 HSE data, pooled over 2 years, increasing numbers and precision of estimates, the rigorous nature of HSE methodology with standardized protocols for measurement by trained interviewers and nurses, all samples being tested in the same laboratory with standardized assays, use of non-response weighting to reduce response bias and use of various SES measures.

The study was limited by its cross-sectional nature, reducing the ability to infer causal relationships. Reverse causation was, however, considered unlikely as the majority of people with CKD are asymptomatic. Non-response weighting is an effective method to avoid bias and maintain representativeness of the sample. ${ }^{40}$ An important limitation was using single samples to test for serum creatinine and albuminuria. Persistence of reduced eGFR levels and elevated ACR to confirm chronicity could not be shown, which could lead to non-differential misclassification. Our methods were similar to those used in NHANES III, but repeat testing of ACR in NHANES showed reduced albuminuria prevalence. ${ }^{2,19}$ The use of single eGFR has also been shown to elevate CKD prevalence estimates. ${ }^{41}$ Confirmation in longitudinal studies would therefore be beneficial. There were too few cases from minority ethnic groups to give robust data on ethnic differences in CKD prevalence. South Asians and Blacks have higher rates of $\mathrm{RRT}^{42}$ but lower prevalence of CKD than Caucasians. ${ }^{43}$ The prevalence of CKD stage $4-5$ is likely to be underestimated as, while the HSE adjusts for nonresponse among the general population in private households, it may not account for some in whom more severe CKD is more common (people in residential care or those unable to participate because of poor health or hospitalization) and may therefore miss individuals with ESRD. Further limitations are lack of data on prevalent CVD and family history, small numbers with macroalbuminuria, lack of information on medication use (differential use of renin angiotensin aldosterone system inhibitors by SES could result in less apparent albuminuria in those with higher SES). Accurately measuring SES in elderly populations is challenging, and non-differential misclassification may bias associations towards the null. ${ }^{44}$ Survivor bias may have reduced socioeconomic gradients, with competing risk of mortality from premature deaths in poorer groups. Heterogeneity of our findings in terms of different measures of SES could be considered a limitation. However, given the challenges of accurately measuring SES 
using any single measure, we believe that the overlap in associations shown here demonstrates support for true association rather than lack of it. A lifecourse approach to assessing SES that is beyond the scope of this study would be needed to fully understand the relationships between different measures and may be an important consideration for future research. $^{39,45}$

\section{Supplementary data}

Supplementary data are available at the Journal of Public Health online.

\section{Acknowledgements}

Our thanks go to Mrs Julie Day, Consultant Clinical Scientist and Dr Linda Wilson at the Freeman Hospital and Royal Victoria Infirmary, Newcastle upon Tyne for their work on the biochemical analyses.

\section{Conflict of interest}

Dr D. O'Donoghue was National Clinical Director for Kidney Care at the Department of Health until April 2013. There are no conflicts of interest to declare. No funding was received by any of the authors to conduct this research. The results presented in this paper have not been published previously in whole or part.

\section{Funding}

The HSE 2009 and 2010 was funded by the Health and Social Care Information Centre (HSCIC) and the UK Department of Health. J.M. is, and M.R. was, funded by HSCIC to work on the HSE series but these secondary analyses were not funded. The HSE funders played no part in the analyses or writing of this paper, nor in the decision to publish.

\section{References}

1 Couser WG, Remuzzi G, Mendis S et al. The contribution of chronic kidney disease to the global burden of major noncommunicable diseases. Kidney Int 2011;80:1258-70.

2 Coresh J, Selvin E, Stevens LA et al. Prevalence of chronic kidney disease in the United States. JAMA 2007;298:2038-47.

3 Hallan SI, Coresh J, Astor BC et al. International comparison of the relationship of chronic kidney disease prevalence and ESRD risk. $J$ Am Soc Nephrol 2006;17:2275-84.
4 Chadban SJ, Briganti EM, Kerr PG et al. Prevalence of kidney damage in Australian adults: The AusDiab kidney study. J Am Soc Nephrol 2003;14:S131-8.

5 Levey AS, Coresh J, Balk E et al. National Kidney Foundation practice guidelines for chronic kidney disease: evaluation, classification, and stratification. Ann Intern Med 2003;139:137-47.

6 Go AS, Chertow GM, Fan D et al. Chronic kidney disease and the risks of death, cardiovascular events, and hospitalization. $N$ Engl J Med 2004;351:1296-305.

7 Matsushita K, van der Velde M, Astor BC et al. Association of estimated glomerular filtration rate and albuminuria with all-cause and cardiovascular mortality in general population cohorts: a collaborative meta-analysis. Lancet 2010;375:2073-81.

8 Gansevoort RT, Matsushita K, van der Velde M et al. Lower estimated GFR and higher albuminuria are associated with adverse kidney outcomes. A collaborative meta-analysis of general and high-risk population cohorts. Kidney Int 2011;80:93-104.

9 Judge A, Caskey FJ, Welton NJ et al. Inequalities in rates of renal replacement therapy in England: does it matter who you are or where you live? Nephrol Dial Transplant 2012;27:1598-607.

10 Roderick P, Clements S, Stone N et al. What determines geographical variation in rates of acceptance onto renal replacement therapy in England? J Health Serv Res Policy 1999;4:139-46.

11 Caskey FJ, Roderick P, Steenkamp R et al. Social deprivation and survival on renal replacement therapy in England and Wales. Kidney Int 2006;70:2134-40.

12 Dudley CRK, Johnson RJ, Thomas HL et al. Factors that influence access to the national renal transplant waiting list. Transplantation 2009;88:96-102.

13 Udayaraj U, Ben-Shlomo Y, Roderick P et al. Social deprivation, ethnicity, and access to the deceased donor kidney transplant waiting list in England and Wales. Transplantation 2010;90:279-85.

14 Ravanan R, Udayaraj U, Ansell D et al. Variation between centres in access to renal transplantation in UK: longitudinal cohort study. BMJ 2010;341:c3451. doi:10.1136/bmj.c3451.

15 Stolzmann KL, Bautista LE, Gangnon RE et al. Trends in kidney transplantation rates and disparities. J Natl Med Assoc 2007;99:923-32.

16 White SL, McGeechan K, Jones M et al. Socioeconomic disadvantage and kidney disease in the United States, Australia, and Thailand. Am J Public Health 2008;98:1306-13.

17 Craig R, Hirani V (eds). Health Survey for England 2009. Health and Lifestyles. Leeds: The NHS Information Centre for health and social care, 2010.

18 Craig R, Mindell J (eds). Health Survey for England 2010. Health and Lifestyles. Leeds: The NHS Information Centre for health and social care, 2011.

19 Martins D, Tareen N, Zadshir A et al. The association of poverty with the prevalence of albuminuria: data from the Third National Health and Nutrition Examination Survey (NHANES III). Am J Kidney Dis 2006;47:965-71.

20 Drey N, Roderick P, Mullee M et al. A population-based study of the incidence and outcomes of diagnosed chronic kidney disease. $\mathrm{Am} \mathrm{J}$ Kidney Dis 2003;42:677-84. 
21 Bello AK, Peters J, Rigby J et al. Socioeconomic status and chronic kidney disease at presentation to a renal service in the United Kingdom. Clin I Am Soc Nephrol 2008;3:1316-23.

22 Levey AS, Stevens LA, Schmid CH et al. A new equation to estimate glomerular filtration rate. Ann Intern Med 2009;150:604-12.

23 The National Statistics Socioeconomic Classification. Office for National Statistics. http://www.ons.gov.uk/ons/guide-method/ classifications/current-standard-classifications/soc2010/soc2010-volume3-ns-sec-rebased-on-soc2010-user-manual/index.html (7 October 2013, date last accessed).

24 Jordan H, Roderick P, Martin D. The Index of Multiple Deprivation 2000 and accessibility effects on health. I Epidemiol Community Health 2004;58:250-7.

25 NICE Clinical Guideline 43. Obesity: guidance on the prevention, identification, assessment and management of overweight and obesity in adults and children. National Institute for Health and Clinical Excellence, 2006.

26 Chronic kidney disease. Early Identification and Management of Chronic Kidney Disease in Adults in Primary and Secondary Care. London: National Institute for Health and Clinical Excellence, 2008.

27 Levey AS, Coresh J, Greene T et al. Using standardized serum creatinine values in the modification of diet in renal disease study equation for estimating glomerular filtration rate. Ann Intern Med 2006;145:247-54.

28 KDIGO 2012 Clinical Practice Guideline for the evaluation and management of chronic kidney disease. Kidney Int Suppl 2013;3:150.

29 Fored CM, Ejerblad E, Fryzek JP et al. Socio-economic status and chronic renal failure: a population-based case-control study in Sweden. Nephrol Dial Transplant 2003;18:82-8.

30 Al-Qaoud TM, Nitsch D, Wells J et al. Socioeconomic status and reduced kidney function in the Whitehall II Study: role of obesity and metabolic syndrome. Am J Kidney Dis 2011;58:389-97.

31 Shoham DA, Vupputuri S, Diez Roux AV et al. Kidney disease in lifecourse socioeconomic context: the Atherosclerosis Risk in Communities (ARIC) Study. Am J Kidney Dis 2007;49:217-26.

32 Kearns B, Gallagher H, de Lusignan S. Predicting the prevalence of chronic kidney disease in the English population: a cross-sectional study. BMC Nephrol 2013;14:49.

33 Sabanayagam C, Shankar A, Saw SM et al. Socioeconomic status and microalbuminuria in an Asian population. Nephrol Dial Transplant 2009;24:123-9.
34 Merkin SS, Coresh J, Roux AV et al. Area socioeconomic status and progressive CKD: the Atherosclerosis Risk in Communities (ARIC) Study. Am J Kidney Dis 2005;46:203-13.

35 McLaren L. Socioeconomic status and obesity. Epidemiol Rev 2007; 29:29-48

36 Lee TC, Glynn RJ, Peña JM et al. Socioeconomic status and incident type 2 diabetes mellitus: data from the Women's Health Study. Plos One 2011;6:e27670. doi:10.1371/journal.pone.0027670.

37 Knott C, Mindell J. Hypertension. Chapter 3 in Health Survey for England-2011, Health, Social Care and Lifestyles. Leeds, UK: The Health and Social Care Information Centre, 2012.

38 Parker JD, Schoendorf KC, Kiely JL. Associations between measures of socioeconomic status and low birth weight, small for gestational age, and premature delivery in the United States. Ann Epidemiol 1994; $4: 271-8$.

39 Shoham DA, Vupputuri S, Kshirsagar AV. Chronic kidney disease and life course socioeconomic status: a review. Adv Chronic Kidney Dis 2005;12:56-63.

40 Van der Heyden J, Demarest S, Van Herck K et al. Association between variables used in the field substitution and post-stratification adjustment in the Belgian health interview survey and non-response. Int J Public Health 2013 [e-pub ahead of publication]. doi:10.1007/ s00038-013-0460-7.

41 de Lusignan S, Tomson C, Harris K et al. Creatinine fluctuation has a greater effect than the formula to estimate glomerular filtration rate on the prevalence of chronic kidney disease. Nephron Clin Pract 2011;117:c213-24.

42 Roderick PJ, Raleigh VS, Hallam L et al. The need and demand for renal replacement therapy in ethnic minorities in England. J Epidemiol Community Health 1996;50:334-9.

43 Dreyer G, Hull S, Aitken Z et al. The effect of ethnicity on the prevalence of diabetes and associated chronic kidney disease. QJM 2009;102:261-9.

44 Grundy E, Holt G. The socioeconomic status of older adults: How should we measure it in studies of health inequalities? I Epidemiol Community Health 2001;55:895-904.

45 Pollitt R, Rose K, Kaufman J. Evaluating the evidence for models of life course socioeconomic factors and cardiovascular outcomes: a systematic review. BMC Publ Health 2005;5:7. 